\title{
DETERMINAÇÃo DE Mn, Cu E Zn EM MATRIZES SALINAS APÓS SEPARAÇÃo E PRÉ-CONCENTRAÇÃo USANDO AMBERLITE XAD-7 IMPREGNADA COM VERMELHO DE ALIZARINA S
}

\author{
Aníbal de Freitas Santos Júnior \\ Departamento de Saúde, Colegiado de Ciências Farmacêuticas, Universidade Estadual de Feira de Santana, Campus Universitário \\ s/n, 44031-460 Feira de Santana - BA \\ Maria das Graças Andrade Korn*, Helena Valli Jaeger, Nívia Maria Silveira Silva e Antonio Celso Spínola Costa \\ Departamento de Química Analítica, Instituto de Química, Universidade Federal da Bahia, Campus de Ondina s/n, 40170-290 \\ Salvador - BA \\ Recebido em 15/10/01; aceito em 8/3/01

\begin{abstract}
DETERMINATION OF Mn, Cu AND Zn IN SALINE MATRICES BY FLAME ATOMIC ABSORPTION SPECTROMETRY AFTER SEPARATION AND PRECONCENTRATION ON AMBERLITE XAD-7 IMPREGNATED WITH ALIZARIN RED S. The aim of this work was to explore the possibility of the application of a non-ionic resin obtained by impregnation of Alizarin Red S (VAS) in Amberlite XAD-7 for manganese, copper and zinc separation and preconcentration in saline matrices. For these system, the metals were quantitatively retained, in the $\mathrm{pH}$ range $8.5-10.0$, by using $0.50 \mathrm{~g}$ of solid phase, stirring time of five minutes and a total mass up to $200 \mu \mathrm{g}$ of each cation. The sorbed elements were subsequently eluted and a fifty-fold, ten-fold and ten-fold preconcentration factor for to $\mathrm{Zn}, \mathrm{Cu}$ and $\mathrm{Mn}$ were obtained, respectively.
\end{abstract}

Keywords: separation; solid phase; metallic ions.

\section{INTRODUÇÃO}

A necessidade de determinação de metais em matrizes salinas, torna-se relevante, principalmente, no que se refere à saúde humana e ao meio ambiente. A determinação de traços de metais em solução de cloreto de sódio 0,9\%, como a solução fisiológica, é clinicamente importante visto que podem complicar o estado de pacientes crônicos em tratamento em hemodiálise ${ }^{1}$. A determinação de elementos traços dissolvidos em água de mar é difícil e constitui um problema de interesse dentro do campo ambiental, uma vez que seus índices devem ser monitorados ${ }^{2}$. Para a determinação de metais nestas matrizes é necessário o desenvolvimento de métodos analíticos apropriados à detecção de micro-quantidades desses elementos.

O manganês é um constituinte essencial do corpo humano, uma vez que está envolvido na ativação de enzimas e na formação de ossos e cartilagens. Sua deficiência pode causar distúrbios no metabolismo, caracterizados por ossos e cartilagens frágeis, degeneração dos discos espinhais, câncer, diminuição da fertilidade, diminuição do crescimento e prejuízo para as funções cerebrais. Porém, no caso de elevados índices de manganês, do ponto de vista toxicológico ${ }^{3,4}$, deve-se suspeitar de exposição ocupacional (metalurgia e mineração), caracterizando seu potencial tóxico, resultando em anorexia, fraqueza, apatia, "loucura mangânica", manias, comportamento violento, tremores simulando Parkinson e depressão.

A importância do zinco na nutrição humana tem sido reportada desde $1934^{6}$, o qual é considerado um elemento traço essencial para o homem, pois está associado à produção de insulina, é componente de mais de 90 enzimas relacionadas com catálise ácido-base e está relacionado com a síntese do DNA e RNA. A deficiência deste metal no organismo pode provocar retardo no crescimento das crianças, falta de apetite, lesões de pele, alopecia, dificuldades de cicatrização, etc. A ingestão de grandes quantidades deste metal resulta em febre, náuseas, vômitos e diarréia.

*e-mail: korn@ufba.br
A utilização do cobre pelo homem é datada dos tempos pré-históricos. Sua essencialidade para o corpo humano foi estabelecida desde $1921^{7}$. Sua deficiência no organismo caracteriza-se por manifestações como anemia, defeitos na formação do tecido conectivo, queratinização e pigmentação deficientes. A ingestão de quantidades elevadas do elemento é prejudicial ao organismo e o efeito nocivo mais pronunciado do excesso de cobre é a doença de Wilson, caracterizada pela falta de coordenação, ataxia e deteriorização mental progressiva.

A Espectrometria de Absorção Atômica com Chama é um método bastante empregado para determinação de metais em matrizes diversas, devido à sua simplicidade e custo relativamente baixo. Entretanto, a análise de amostras em matrizes com alto teor salino é dificultada devido a problemas causados pela alta concentração de eletrólitos, tais como entupimento do capilar e alterações no processo de nebulização, que resultam em baixa sensibilidade e precisão. Portanto, procedimentos de separação e pré-concentração são necessários antes da aplicação desta técnica analítica a fim de reduzir os possíveis erros. Dentre os métodos utilizados, destaca-se a extração líquido-sólido, que se baseia no uso de suportes sólidos modificados por agentes complexantes, com aplicações em processos em coluna e em batelada. A separação seletiva e a pré-concentração de traços de metais em soluções aquosas têm sido extensivamente investigadas com um grande número de materiais ${ }^{8,9}$. Atualmente, os suportes mais utilizados para a imobilização de reagentes orgânicos têm sido as resinas não-iônicas $(\mathrm{XADs})^{10-15}$ e de troca aniônica (Dowex 1X8, Amberlyst A-26, etc.) e outros adsorventes, tais como celulose, sílica-gel, espumas de poliuretano, carvão ativado e alumina.

O objetivo deste trabalho é estudar as condições de separação e pré-concentração de $\mathrm{Mn}, \mathrm{Cu}$ e $\mathrm{Zn}$ utilizando uma metodologia de extração líquido-sólido, para posterior determinação de $\mathrm{Mn}, \mathrm{Cu}$ e $\mathrm{Zn}$ em amostras salinas, onde o reagente 1,2-dihidroxiantraquinona3-sulfonato de sódio, Vermelho de Alizarina S (VAS), é usado como agente complexante e a resina não-iônica Amberlite XAD-7, como suporte sólido. O reagente Vermelho de Alizarina S começou a ser 
empregado com propósitos analíticos como reagente colorimétrico por Atack ${ }^{16}$ em 1915 e, até hoje, o VAS é empregado com propósitos analíticos de forma satisfatória ${ }^{17-24}$.

\section{PARTE EXPERIMENTAL}

\section{Soluções e reagentes}

Todos os reagentes usados foram de grau analítico e as soluções preparadas com água bidestilada e deionizada.

Soluções estoque de referência $1000 \mu \mathrm{g} \mathrm{mL}^{-1}$ : As soluções estoque dos cátions metálicos $\mathrm{Cu}^{2+}, \mathrm{Mn}^{2+}$ e $\mathrm{Zn}^{2+}, 1000 \mu \mathrm{g} \mathrm{mL} \mathrm{m}^{-1}$ foram preparadas a partir das respectivas soluções contidas em ampolas Titrisol, da Merck, por diluição com água deionizada com adição de ácido nítrico suficiente para uma concentração final de $10 \%$ (v/v) de ácido. As soluções foram estocadas em frascos de polietileno previamente descontaminados.

Solução multielementar de $\mathrm{Cu}^{2+}, \mathrm{Mn}^{2+}$ e $\mathrm{Zn}^{2+} 50 \mu \mathrm{g} \mathrm{mL}^{-1}$ : Esta solução foi preparada a partir de alíquotas apropriadas das soluções estoque de referência dos diversos cátions metálicos, para obter concentração final de $50 \mu \mathrm{g} \mathrm{mL}{ }^{-1}$ de cada íon metálico.

Soluções tampão: glicina/ $\mathrm{HCl}(\mathrm{pH} \mathrm{3,0);} \mathrm{ácido} \mathrm{acético/acetato}$ de sódio ( $\mathrm{pH} 5,0)$; ácido cítrico/citrato de sódio ( $\mathrm{pH} 6,0)$; Tris/HCl ( $\mathrm{pH} 7,0$ e 8,0); amônia/cloreto de amônio (pH 8,5 a 10,0)

Soluções dos ácidos para estudo do tipo e concentração de eluente: Soluções dos ácidos $\mathrm{HNO}_{3}, \mathrm{HCl}$ e $\mathrm{H}_{2} \mathrm{SO}_{4}$ foram preparadas por diluição de quantidades apropriadas dos respectivos ácidos concentrados, com água deionizada.

Soluções de ions para estudo de efeito de eletrólitos: Foram preparadas soluções em diferentes percentagens $(\mathrm{m} / \mathrm{v}) \mathrm{de} \mathrm{Na}^{+}, \mathrm{K}^{+}, \mathrm{Ca}^{2+}$, $\mathrm{Mg}^{2+} \mathrm{e} \mathrm{Ba}^{2+}$, a partir dos respectivos sais na forma de cloreto, e em $\mathrm{Cl}^{-}, \mathrm{SO}_{4}^{2-}$ e $\mathrm{PO}_{4}^{3-}$, a partir dos sais de sódio, por dissolução de quantidades adequadas dos sais p.a. e diluição com água deionizada a volume apropriado.

Adsorvente polimérico não-iônico (Amberlite XAD-7): marca Aldrich Chemical Company, com granulometria de 2-60 mesh.

Vermelho de Alizarina $S$ (1-2-dihidroxiantraquinona-3-sulfonato de sódio): marca Merck, 360,28 $\mathrm{g} \mathrm{mol}^{-1}$.

\section{Instrumental}

As medidas de absorvância foram efetuadas utilizando um espectrômetro de absorção atômica com chama (FAAS), marca Varian, modelo 220, com corretor de "background" de lâmpada de deutério e lâmpadas de cátodo oco de zinco, cobre e manganês e chama ar/acetileno com especificações contidas na Tabela 1. Os ajustes de $\mathrm{pH}$ foram feitos em potenciômetro Digimed modelo DM 20 (com eletrodo de vidro combinado DME-MVI).

Tabela 1. Condições de operação do espectrômetro de absorção atômica

\begin{tabular}{lccc}
\hline Parâmetro & $\mathrm{Cu}$ & $\mathrm{Zn}$ & $\mathrm{Mn}$ \\
\hline Comprimento de onda $(\mathrm{nm})$ & 324,8 & 213,9 & 279,5 \\
Corrente da lâmpada (mA) & 4 & 5 & 5 \\
Largura de fenda (nm) & 0,5 & 1,0 & 0,2 \\
Chama & $\mathrm{Ar} /$ & $\mathrm{Ar} /$ & $\mathrm{Ar} /$ \\
& Acetileno & Acetileno & Acetileno \\
Modo de calibração & Linear & Linear & Linear \\
$\left(\mu \mathrm{gL}^{-1}\right)$ & $0-1,2$ & $0-1,0$ & $0-1,2$ \\
\hline
\end{tabular}

\section{Ativação da resina Amberlite XAD-7}

A ativação do suporte sólido antes de seu uso constitui uma etapa de purificação deste material, pois visa eliminar possíveis interferentes/contaminantes presentes na resina, assim como garantir que os sítios ativos estejam livres para facilitar a impregnação com o reagente e posterior retenção dos íons metálicos. Pesou-se $100 \mathrm{~g}$ da resina, os quais foram tratados com uma solução contendo etanol, ácido clorídrico concentrado e água deionizada (2:1:1), por um período de $24 \mathrm{~h}$. A resina foi lavada com água deionizada até o filtrado obtido apresentar um valor de $\mathrm{pH}$ entre 6,00 e 7,00. Procedeu-se a filtração a vácuo e secagem em dessecador.

\section{Impregnação da resina com VAS e caracterização do material}

Inicialmente, foram pesados $10 \mathrm{~g}$ de resina e $0,5 \mathrm{~g}$ de VAS e, em seguida, levados a um erlenmeyer com capacidade de $500 \mathrm{~mL}$, sendo então acrescentados $250 \mathrm{~mL}$ de água deionizada e agitados, com um agitador mecânico, por um período de $3 \mathrm{~h}$. Procedeu-se à filtração a vácuo e secagem em dessecador por um período de $24 \mathrm{~h}$. A resina impregnada seca foi caracterizada por Espectroscopia no Infravermelho, utilizando um aparelho com transformada de Fourier (FTIR). Foram obtidos espectros das resinas puras, do reagente VAS e da resina impregnada com o reagente VAS. Os espectros foram obtidos em pastilhas de $\mathrm{KBr}$ na proporção 1:1 (amostra : KBr).

\section{Separação e pré-concentração de $\mathrm{Cu}, \mathrm{Mn}$ e Zn}

Estudos univariados para otimização do procedimento analítico foram desenvolvidos em triplicata. Assim, a 1,0 $\mathrm{g}$ da fase sólida Amberlite XAD-7/VAS foram adicionadas alíquotas de 1,0 mL de uma solução contendo de 2,5 a $1000 \mu \mathrm{g}$ de cada metal e $10 \mathrm{~mL}$ de tampão amoniacal pH 9,0. O tempo de agitação foi estudado no intervalo de 1 a 60 min, usando agitador mecânico. Após etapa de separação e pré-concentração, o sistema foi filtrado com papel de filtração rápida e eluído com alíquotas de 1,0 a 50,0 mL de soluções ácidas. Os ácidos avaliados foram $\mathrm{HCl}, \mathrm{HNO}_{3}$ e $\mathrm{H}_{2} \mathrm{SO}_{4}$ em concentrações de 0,5 a $7 \mathrm{~mol} \mathrm{~L}^{-1}$. Após eluição, as medições das absorvâncias foram efetuadas empregando FAAS, nas condições mostradas na Tabela 1.

\section{RESULTADOS E DISCUSSÃO}

\section{Caracterização do reagente VAS e da fase sólida Amberlite XAD-7/VAS}

A imobilização de um reagente orgânico sobre um suporte sólido pode ocorrer por troca iônica, por adsorção física ou por superposição de ambos os fenômenos. O processo de impregnação constitui uma etapa importante da metodologia, uma vez que é necessário garantir que o reagente esteja retido na resina. A fase sólida, obtida após a impregnação do reagente VAS sobre a resina não-iônica Amberlite XAD-7, é resultante de um processo físico (adsorção física) e não por troca iônica, pois o reagente é adsorvido pelos poros da resina, que é um polímero adsorvente não-iônico.

No espectro do reagente VAS, pode-se evidenciar bandas de absorção em $3467 \mathrm{~cm}^{-1}$, características de hidroxila fenólica; a região entre $1636 \mathrm{e} 1664 \mathrm{~cm}^{-1}$, referente às carbonilas que compõem o grupamento antraquinônico; as regiões entre 1204 e $1290 \mathrm{~cm}^{-1}$ referentes às ligações do carbono aromático com o oxigênio fenólico, e entre 1040 e $1070 \mathrm{~cm}^{-1}$, características de deformação axial da ligação $\mathrm{S}=\mathrm{O}$ da molécula de VAS. Os espectros da resina pura mostraram bandas de absorção que caracterizaram a estrutura da Amberlite 
XAD-7, um polímero de acrílico mais divinilbenzeno não-iônico alifático com ligações cruzadas. Após ser impregnada com VAS, os espectros evidenciaram bandas de absorção que caracterizam um processo de impregnação da resina por adsorção física.

Antes de iniciar o estudo das variáveis do sistema, procurou-se verificar a potencialidade da resina sem o reagente VAS e concluiuse que era necessária a sua presença para que se verificasse retenção quantitativa dos íons metálicos ( $\geq 95 \%)$. Após a obtenção da fase sólida utilizada neste trabalho, vários parâmetros foram analisados a fim de se otimizar o sistema para posterior aplicação em amostras reais: efeito do $\mathrm{pH}$, tempo de complexação, natureza e concentração de eluente, quantidade de VAS impregnado no suporte sólido, caracterização do material, capacidade da fase sólida e efeito de íons estranhos.

\section{Estudo do efeito do pH}

Visando verificar a eficiência dos sistemas XAD-7/VAS, na retenção e recuperação dos íons metálicos, uma ampla faixa de $\mathrm{pH}$ foi empregada neste estudo. Os valores de $\mathrm{pH}$ da fase líquida foram medidos antes e depois da etapa de separação/pré-concentração. A melhor faixa de $\mathrm{pH}$ para recuperação quantitativa de todos os metais é de 8,5 a 10,0 , sendo que o valor selecionado para a continuidade dos experimentos foi $\mathrm{pH}$ 9,0. Os percentuais de recuperação observados para os diversos valores de $\mathrm{pH}$ estão apresentados na Figura 1.

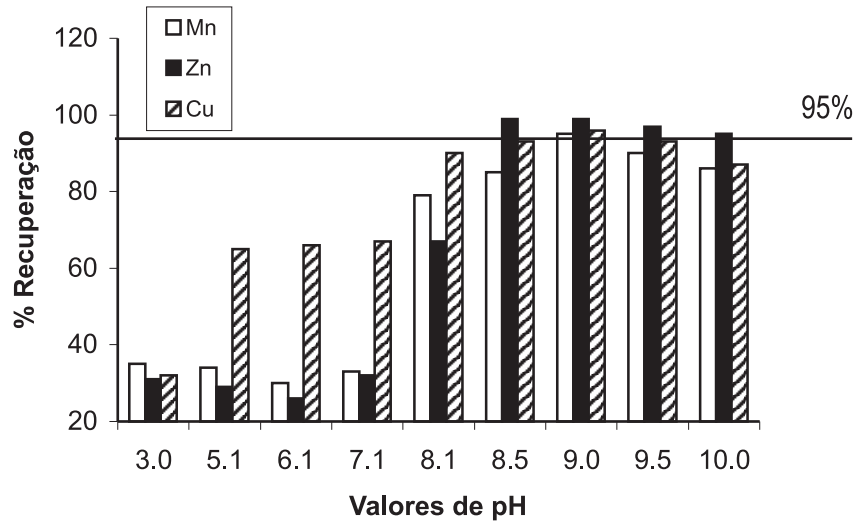

Figura 1. Variação do percentual de recuperação após separação e préconcentração de $\mathrm{Mn}$, Cu e Zn utilizando a fase sólida XAD-7/VAS de acordo com o valor de $\mathrm{pH}$

Um ligeiro decréscimo é observado para $\mathrm{Zn}$ e $\mathrm{Cu}$ acima de $\mathrm{pH}$ 9,5, o que pode ser atribuído à formação de amino-complexos destes íons.

$\mathrm{O}$ valor de $\mathrm{pH}$ está associado à formação do complexo e sua extração, e varia dependendo do extrator utilizado e da forma como ocorre a interação entre o reagente orgânico e a resina. Com isso, supõe-se que a variação da percentagem de extração dos íons metálicos, nos diferentes valores de $\mathrm{pH}$, possa estar relacionada com o comprometimento da disponibilidade dos centros ativos do VAS após impregnação nos suportes sólidos.

\section{Estudo do tempo de complexação}

Para avaliar a cinética de retenção, a fim de se determinar o tempo de contato necessário entre a fase aquosa e a fase sólida de forma a se obter uma separação quantitativa dos íons metálicos, foram estudados diferentes tempos (1, 2, 3, 4, 5, 10, 15, 30 e $60 \mathrm{~min}$ ) para o sistema XAD-7/VAS. Os percentuais de recuperação obtidos, para os diversos tempos de contato, indicaram que o tempo de 5 minutos é suficiente para a retenção satisfatória dos metais em estudo. Estes resultados indicam uma cinética rápida de complexação, o que torna o método proposto bastante promissor no que diz respeito ao tempo de análise.

\section{Estudo do eluente}

\section{Concentração e natureza do eluente}

Considerando a natureza do complexo formado entre os íons metálicos e VAS, foram realizados ensaios utilizando-se como eluentes ácido clorídrico, ácido nítrico e ácido sulfúrico, nas concentrações 0,$5 ; 1,0 ; 2,0 ; 3,0 ; 5,0$ e $7 \mathrm{~mol} \mathrm{~L}^{-1}$. Este experimento teve como principal objetivo selecionar a natureza e a concentração mínima do eluente mais indicado para uma recuperação quantitativa dos metais, ou seja, $\geq$ a $95 \%$. Os ácidos clorídrico e nítrico mostraram-se eficientes para a extração de $\mathrm{Mn}, \mathrm{Zn}$ e $\mathrm{Cu}$, nas concentrações de 1 a $3 \mathrm{~mol} \mathrm{~L}^{-1}$, ao passo que o ácido sulfúrico mostrou-se eficiente apenas para $\mathrm{Zn}$ e $\mathrm{Cu}$, na faixa de concentração de $0,5 \mathrm{a} 3 \mathrm{~mol} \mathrm{~L}^{-1}$. À medida que se aumentou a concentração do ácido, verificou-se uma diminuição do sinal analítico.

Optou-se por utilizar uma solução de ácido nítrico $3 \mathrm{~mol} \mathrm{~L}^{-1} \mathrm{como}$ eluente ideal para o sistema XAD-7/VAS, pois foram obtidos valores de recuperação superiores a $95 \%$ para todos os metais em estudo.

\section{Quantidade de eluente}

Com o objetivo de utilizar as quantidades mínimas necessárias de $\mathrm{HNO}_{3} 3$ mol L-1 investigou-se este parâmetro e os resultados são mostrados na Figura 2. Observou-se que, a partir de $4 \mathrm{~mL}$ de $\mathrm{HNO}_{3}$ $3 \mathrm{~mol} \mathrm{~L}^{-1}$ já se consegue obter um percentual de recuperação acima de $95 \%$. Para os experimentos a serem realizados a seguir, optou-se por utilizar $5 \mathrm{~mL}$ de uma solução de $\mathrm{HNO}_{3} 3 \mathrm{~mol} \mathrm{~L}^{-1}$.

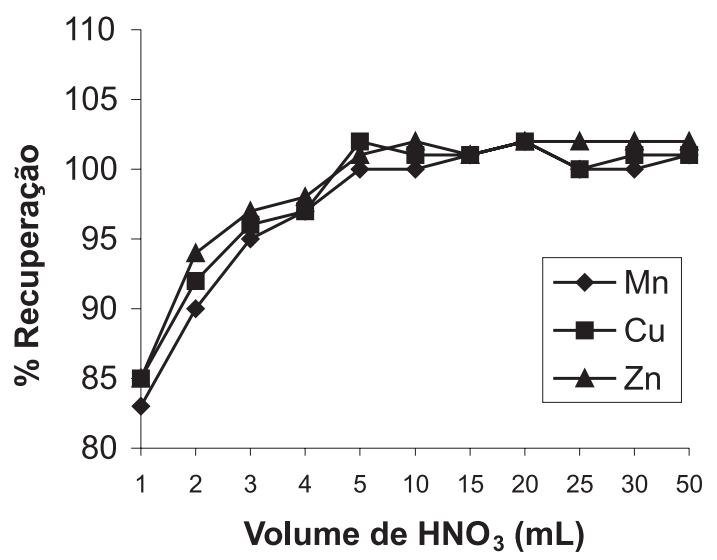

Figura 2. Percentual de recuperação de Mn, Cu e Zn após separação e préconcentração utilizando a fase sólida XAD-7/VAS em relação à eluição com diferentes volumes de $\mathrm{HNO}_{3} 3 \mathrm{~mol} \mathrm{~L}^{-1}$

Estudo da quantidade de VAS impregnado nos suportes sólidos

Com o objetivo de avaliar a quantidade de VAS a ser impregnada na resina XAD-7, desenvolveu-se um estudo variando a quantidade de reagente e fixando a quantidade de suporte. As quantidades de 
VAS colocadas em contato com $5,0 \mathrm{~g}$ de resina foram 0,$025 ; 0,050$; 0,$125 ; 0,250 ; 0,375$ e $0,500 \mathrm{~g}$. Os resultados obtidos indicaram que uma massa de $0,050 \mathrm{~g}$ foi suficiente para impregnar 5,0 $\mathrm{g}$ de VAS XAD-7, uma vez que se verificou uma retenção quantitativa para os íons metálicos estudados. Porém, para os experimentos complementares optou-se por utilizar uma fase sólida obtida após contato de 5,0 $\mathrm{g}$ de resina Amberlite XAD-7 com uma massa de 0,125 g de VAS, uma vez que se pretendeu assegurar que o maior número de poros possíveis da resina fossem ocupados pelo reagente VAS, garantindo a aplicabilidade da fase sólida proposta para amostras com concentrações maiores dos íons metálicos estudados.

\section{Estudo da capacidade da fase sólida}

Neste experimento, pretendeu-se avaliar a capacidade da fase sólida em reter os íons metálicos. Para tal, foram adicionadas alíquotas de solução multielementar com concentração $50 \mu \mathrm{g} \mathrm{mL}^{-1}$ de forma que, nas soluções finais, resultassem $0 ; 2,5 ; 5 ; 10 ; 25 ; 50 ; 100 ; 200 ; 500$ e $1000 \mu \mathrm{g}$ de cada íon metálico. Para comprovação do balanço de massa, os metais foram determinados tanto no filtrado da fase de separação, como no filtrado da recuperação ácida. Os resultados evidenciam que para Mn foram obtidos fatores de recuperação acima de 95\%, para soluções contendo $2,5 \mu \mathrm{g}$ até $500 \mu \mathrm{g}$ deste metal/grama de resina impregnada. Por outro lado, verificou-se que a retenção quantitativa de $\mathrm{Cu}$ e Zn ocorreu em soluções contendo 2,5 $\mu \mathrm{g}$ até, no máximo, 200 $\mu \mathrm{g}$. Estes resultados indicam que o método proposto pode ser aplicado em matrizes salinas diversas que apresentem diferentes faixas de concentração dos analitos estudados, sem prejuízos à exatidão e precisão.

O sistema XAD-7/VAS apresentou uma recuperação quantitativa quando utilizada até 6 vezes. Acima deste número observou-se um desprendimento do VAS da superfície da resina Amberlite XAD7. Tal fato pode ser creditado à forma de impregnação do suporte, uma vez que esta ocorre através de um processo de adsorção física.

\section{Efeito de íons estranhos sobre a recuperação dos metais}

Nessa etapa do trabalho foi desenvolvido um estudo visando avaliar a tolerância do sistema XAD-7/VAS quanto à presença de metais alcalinos e alcalinos terrosos e ânions presentes em matrizes salinas. Foram preparadas soluções salinas contendo $20 \%$ (m/v) dos seguintes sais: $\mathrm{NaCl}, \mathrm{KCl}, \mathrm{CaCl}_{2}, \mathrm{MgCl}_{2}, \mathrm{BaCl}_{2}, \mathrm{Na}_{3} \mathrm{PO}_{4}$ e $\mathrm{Na}_{2} \mathrm{SO}_{4}$; a partir destas soluções foram retiradas alíquotas para que se obtivesse concentração final variada destes sais de $0 ; 0,5 ; 1,0 ; 3,0$ e 5,0\% (m/v). Para Mn, $\mathrm{Na}_{2} \mathrm{SO}_{4}, \mathrm{Mg}^{2+}$ e $\mathrm{Ba}^{2+}$ são tolerados até uma concentração de $5,0 \%$, $0,5 \%$ e $3,0 \%$, respectivamente, e $\mathrm{Ca}^{2+}$ interfere consideravelmente. Para $\mathrm{Cu}$ e $\mathrm{Zn}$, a presença de $\mathrm{NaCl}, \mathrm{Na}_{2} \mathrm{SO}_{4}, \mathrm{Na}_{3} \mathrm{PO}_{4}$ e $\mathrm{KCl}$ não interfere quantitativamente na determinação do metal, até uma concentração de $5,0 \%$ e $\mathrm{Mg}^{2+}, \mathrm{Ba}^{2+}$ e $\mathrm{Ca}^{2+}$ interferem consideravelmente. O comportamento encontrado para estes interferentes pode ser justificado pelas informações encontradas nos estudos desenvolvidos por Estela e colaboradores $^{21}$ e Singh e colaboradores ${ }^{25}$, os quais relatam interferência destes íons metálicos nas determinações usando Vermelho de Alizarina $\mathrm{S}$. Entretanto, de acordo com Kennish ${ }^{26}$, as faixas de concentrações esperadas para $\mathrm{Ba}, \mathrm{Ca}$ e $\mathrm{Mg}$ em água do mar são insignificantes frente às concentrações de $\mathrm{Mn}, \mathrm{Cu}$ e $\mathrm{Zn}$. Portanto, estas interferências não devem ser significativas, quando da aplicação do sistema proposto para determinação destes íons metálicos, na referida matriz.

\section{Influência do volume de amostra sobre a recuperação dos metais}

Com o objetivo de verificar a influência do volume de amostra na extração quantitativa dos metais, foram realizados testes para avaliar o fator de pré-concentração dos metais no método proposto. Uma vez que o reagente VAS é solúvel em água, esse teste tem caráter relevante neste trabalho, pois é necessário avaliar até que ponto a fase sólida é eficiente. Foram utilizados $5 \mu \mathrm{g}$ de íons metálicos, $\mathrm{pH}$ 9,0 e 5 min de agitação. O volume total de solução foi variado de 10 a $1000 \mathrm{~mL}$. A fase residual contendo a fase sólida com os metais complexados, após filtração, foi eluída com $5 \mathrm{~mL}$ de $\mathrm{HNO}_{3} 3 \mathrm{~mol} \mathrm{~L}^{-1}$. $\mathrm{Mn} \mathrm{e} \mathrm{Cu}$ são recuperados quantitativamente para um volume de fase aquosa de até 50 $\mathrm{mL}$. Observou-se, também, que se obteve um percentual de recuperação em torno de $85-90 \%$ para Mn, para um volume de até $100 \mathrm{~mL}$ de solução. Por outro lado, $\mathrm{Zn}$ pode ser recuperado quantitativamente para um volume de fase aquosa de até $250 \mathrm{~mL}$, com percentuais de recuperação entre 92 e $105 \%$. Com isso, foram obtidos fatores de préconcentração de até 10 vezes para $\mathrm{Mn}$ e Cu e de até 50 vezes para $\mathrm{Zn}$, utilizando-se o sistema XAD-7/VAS.

\section{Procedimento de pré-concentração}

Após determinadas as condições ótimas para o sistema Amberlite $\mathrm{XAD}-7 / \mathrm{VAS}$, foi recomendado um procedimento analítico, apresentado na Figura 3, a fim de se aplicar a metodologia proposta em amostras reais.

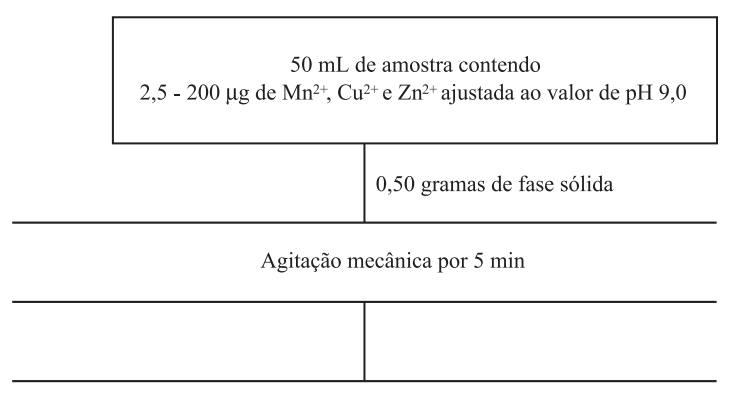

Filtrar em funil de vidro com papel de filtro

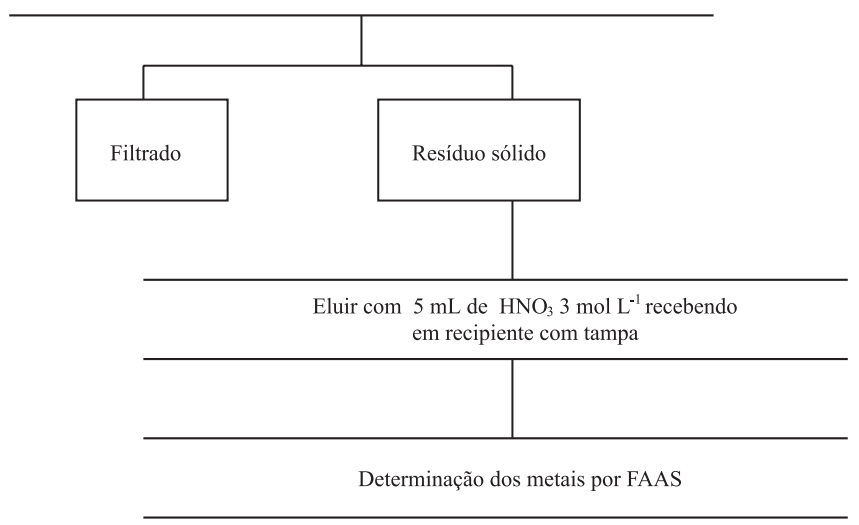

Figura 3. Fluxograma do Procedimento Analítico sugerido para o sistema Amberlite XAD-7/NAS

\section{Limites de detecção (LD) e limite de quantificação (LQ) do método}

Para determinar os limites de detecção (LD) e de quantificação (LQ) das metodologias propostas foram realizados 30 ensaios em branco em dias alternados, durante o período em que a etapa experimental foi executada.

$\mathrm{O}$ valor do LD foi obtido multiplicando-se o desvio padrão referente à média dos 30 ensaios em branco por 3, ou seja, (3s) e o LQ, 
multiplicando-se o desvio padrão por 10 , isto é $(10 \mathrm{~s})^{27}$. Os valores obtidos são apresentados na Tabela 2 .

Tabela 2. Valores de Limite de Detecção (LD) e Quantificação (LQ) para o sistema XAD-7 / VAS empregando FAAS

\begin{tabular}{|c|c|c|}
\hline Metal & $\begin{array}{l}\text { Limite de Detecção } \\
\left.\qquad(\mu \mathrm{g} \mathrm{L})^{-1}\right)\end{array}$ & $\begin{array}{c}\text { Limite de Quantificação } \\
\left(\mu \mathrm{g} \mathrm{L}^{-1}\right)\end{array}$ \\
\hline $\mathrm{Mn}$ & 32,0 & 105,0 \\
\hline $\mathrm{Zn}$ & 29,0 & 98,0 \\
\hline $\mathrm{Cu}$ & 10,0 & 35,0 \\
\hline
\end{tabular}

(a) 3 vezes o desvio padrão de 30 ensaios em branco expresso em concentração. (b) 10 vezes o desvio padrão de 30 ensaios em branco expresso em concentração.

\section{APLICAÇÕES}

\section{Determinação de metais em amostras salinas}

O método foi aplicado para separação e pré-concentração de Mn, $\mathrm{Cu}$ e $\mathrm{Zn}$ em solução fisiológica e água de mar, da cidade de Salvador-Bahia. Amostras de solução fisiológica foram obtidas em farmácias da cidade de Salvador. Três amostras de água de mar foram coletadas em diferentes praias da cidade de Salvador (Praia do Porto da Barra, Praia de Ondina e Praia do Rio Vermelho), utilizando-se o método da adição de analitos. Para $50 \mathrm{~mL}$ de cada amostra foram adicionados $5 \mu \mathrm{g}$ de cada metal, a partir de volume adequado de uma solução multielementar de $\mathrm{Cu}^{2+}, \mathrm{Zn}^{2+}$ e $\mathrm{Mn}^{2+} 50 \mu \mathrm{g} \mathrm{mL}$.
Os resultados obtidos, apresentados na Tabela 3, indicam que as concentrações de $\mathrm{Mn}, \mathrm{Zn}$ e $\mathrm{Cu}$ nas amostras de solução fisiológica analisadas são relativamente baixas, o que permite fazer uso das mesmas, em concentrados de diálise por via endovenosa. Os resultados obtidos para água de mar estão de acordo com os valores estabelecidos pelo Conselho Nacional do Meio Ambiente (CONAMA), o qual estabelece, na resolução nº 20 de 1986, os teores máximos das substâncias potencialmente prejudiciais ao homem em águas salinas.

\section{CONCLUSÃO}

Com base nos dados obtidos na realização deste trabalho, o sistema mostrou-se eficiente para a separação e pré-concentração de $\mathrm{Mn}, \mathrm{Zn}$ e $\mathrm{Cu}$ em matrizes salinas. O sistema apresentou uma rápida cinética de reação para complexação dos íons metálicos (5 min), um consumo baixo de eluente e reagentes, maior estabilidade frente aos eletrólitos interferentes estudados e maiores fatores de pré-concentração. A desvantagem deste sistema é a liberação do reagente orgânico do suporte quando se utiliza uma maior quantidade de amostra e maior tempo de contato entre as mesmas, devido à solubilidade do reagente em água. Por outro lado, como perspectivas, pode-se desenvolver uma metodologia para Análise por Injeção em Fluxo (FIA), visando automação deste sistema.

O sistema estudado foi aplicado em análise de solução fisiológica (teor salino de $0,9 \%$ ) e água de mar (teor salino de $~ 3,5 \%$ ). Testes de recuperação com adição de $5 \mu \mathrm{g}$ de $\mathrm{Mn}, \mathrm{Cu}$ e $\mathrm{Zn}$ revelaram eficiência no que diz respeito à exatidão e à precisão do procedimento recomendado, com retenção quantitativa maior ou igual a $95 \%$.

Tabela 3. Valores obtidos de $\mathrm{Mn}, \mathrm{Cu}$ e $\mathrm{Zn}$ em amostras de solução fisiológica e água do mar sem e com adição de analitos empregando o sistema Amberlite XAD-7/VAS

\begin{tabular}{|c|c|c|c|c|c|c|}
\hline \multirow[t]{2}{*}{ Amostra } & \multicolumn{2}{|c|}{$\mathrm{Mn}$} & \multicolumn{2}{|c|}{$\mathrm{Cu}$} & \multicolumn{2}{|c|}{$\mathrm{Zn}$} \\
\hline & $\begin{array}{l}\text { Sem adição } \\
\left(\mu \mathrm{g} \mathrm{mL} \mathrm{mL}^{-1}\right)\end{array}$ & $\begin{array}{l}\text { Com adição } \\
\left(\mu \mathrm{g} \mathrm{mL} \mathrm{mL}^{-1}\right)\end{array}$ & $\begin{array}{c}\text { Sem adição } \\
\left(\mu \mathrm{g} \mathrm{mL}^{-1}\right)\end{array}$ & $\begin{array}{l}\text { Com adição } \\
\left(\mu \mathrm{g} \mathrm{mL} \mathrm{mL}^{-1}\right)\end{array}$ & $\begin{array}{l}\text { Sem adição } \\
\left(\mu \mathrm{g} \mathrm{mL} \mathrm{mL}^{-1}\right)\end{array}$ & $\begin{array}{c}\text { Com adição } \\
\left(\mu \mathrm{g} \mathrm{mL}^{-1}\right)\end{array}$ \\
\hline Solução Fisiológica 1 & $<\mathrm{LD}$ & $1,03 \pm 0,02$ & $0,022 \pm 0,001$ & $0,99 \pm 0,04$ & $0,028 \pm 0,002$ & $1,09 \pm 0,03$ \\
\hline Solução Fisiológica 2 & $<\mathrm{LD}$ & $1,02 \pm 0,03$ & $0,019 \pm 0,002$ & $1,00 \pm 0,06$ & $0,021 \pm 0,004$ & $1,03 \pm 0,01$ \\
\hline Praia do Porto da Barra & $0,115 \pm 0,002$ & $1,12 \pm 0,01$ & $0,061 \pm 0,001$ & $1,07 \pm 0,02$ & $0,112 \pm 0,002$ & $1,24 \pm 0,04$ \\
\hline Praia de Ondina & $0,123 \pm 0,003$ & $1,20 \pm 0,04$ & $0,060 \pm 0,001$ & $1,07 \pm 0,03$ & $0,110 \pm 0,004$ & $1,25 \pm 0,03$ \\
\hline Praia do Rio Vermelho & $0,117 \pm 0,001$ & $1,19 \pm 0,03$ & $0,053 \pm 0,003$ & $1,05 \pm 0,02$ & $0,092 \pm 0,003$ & $1,21 \pm 0,03$ \\
\hline
\end{tabular}

\section{AGRADECIMENTOS}

Os autores agradecem aos órgãos de fomento (CNPq, CAPES e SEPLANTEC/CADCT).

\section{REFERÊNCIAS}

1. Soylak, M.; Elci, L.; Dogan, M.; Anal. Lett. 1993, 26, 1997.

2. Herruzo, F. H.; Garcia, I. N.; Coronel, F. J. M.; Jimenez, J. J. R.; Afinidad 1987, XLVI, 409.

3. Tanaka, S. Em Occupational Medicine; Edt. Mosby - Year Book Inc.: USA, 1994.

4. Galvão, L. A. C.; Corey, G. Em Manganeso-Serie Vigilancia; Centro Panamericano de Ecologia Humana y Salud: México, 1987.

5. Tsalev, D. L. Em Atomic Absorption Spectrometry in Occupational and Enviromental Health Practice; CRC Press: USA, 1984, vol. II.

6. Prasad, A. S.; Oberleas, D.; Em Trace Elements in Human Health and Disease, vol. 1, Academic Press: New York, 1976.

7. Sargentelli, V.; Mauro, A. E.; Massabi, A .C.; Quim. Nova 1996, 19, 290.

8. Marina, M. L.; Gonzalez, V.; Rodríguez, A . R.; Microchem. J. 1986, 33, 275.

9. Zhang, M.; Florence, T. M.; Anal. Chim. Acta 1987, 197, 137.

10. Ferreira, S. L. C.; Ferreira, J. R.; Dantas, A. F.; Lemos, V. A .; Araújo, N. M. L.; Costa, A. C. S.; Talanta 2000, 50, 1253.
11. Ferreira, S. L. C.; Brito, C. F.; Anal. Sci. 1999, 15, 189.

12. Soylak, M.; Sahin, U.; Elci, L.; Anal. Chim. Acta 1996, 322, 111.

13. Soylak, M.; Dogan, M.; Trace Elem. Eletroly. 1996, 13, 130.

14. Soylak, M.; Divrikli, U.; Dogan, M.; J. Trace Microprobe T. 1997, 15, 197.

15. Tewari, P. K.; Singh, A. K.; Fresenius' J. Anal. Chem. 2000, 367, 562

16. Atack, W. F.; J. Soc. Chem. Ind. 1915, 34, 936.

17. Chimpalee, N.; Chimpalee, D.; Boonyanitcha Yakul, B.; Burns, D. T.; Anal. Chim. Acta 1993, 282, 643

18. Pereira, A. V.; Marcolino-Junior, L. H.; Fatibello-Filho, O.; Quim. Nova 2000, 23, 167

19. Saxena, R.; Singh, A. K.; Sambi, S. S.; Anal. Chim. Acta 1994, 295, 199.

20. Nagahiro, T.; Wang, G. F.; Satake, M.; Microchem. J. 1995, 52, 247.

21. Estela, J. M.; Caro, A.; Forteza, R.; Cerda, V.; Termochim. Acta 1992, 200, 467

22. Abd El Wahed, M. G.; Metwally, S. M.; El Manakhly, K. A .; Hammad, H. A.; Can. J. Anal. Sci. Spectrosc. 1998, 43, 37.

23. Mouchrek, V. E.; Chierice, G. O.; Marques, A. L. B.; Quim. Nova 1999 22, 312 .

24. Corsini, A.; Wade, G.; Wan, C.; Prasad, S.; Can. J. Chem. 1987, 65, 915.

25. Singh, R. P.; Fresenius'. J. Anal. Chem. 1972, 258, 125.

26. Kennish, M. J. Em Practical Handbook of Marine Science; $2^{\text {a }}$ ed., CRC Press: USA, 1994.

27. Meier, P. C.; Zund, R. E. Em Chemical Analysis - Statistical Methods in Analytical Chemistry; John Wiley \& Sons Inc: New York, 1993, cap. 1-3. 